\title{
A CIENCIA CIERTA, EL PAPEL DE LOS PAPERS (EFECTOS DEL ARRIBISMO CIENTÍFICO EN LAS HUMANIDADES $)^{1}$
}

\author{
Pablo Chiuminatto \\ Facultad de Letras, Universidad Católica, Santiago.
}

\section{LAS CIENCIAS Y LA OMISIÓN DEL FUNDAMENTO ESTÉTICO DEL PENSAMIENTO}

La ampliación de la noción de ciencia a todos los ámbitos del saber instala uno de los paradigmas más poderosos de los últimos siglos en las humanidades. Este giro histórico marcó una diferencia drástica para las disciplinas que tradicionalmente no estaban bajo ese lema, a pesar de que por siglos compartieron un mismo escaño en dicho panteón.

Si proyectamos esta perspectiva, ficticiamente, en el modelo de clasificación decimal de Dewey, podemos ver que las disciplinas que antes estaban en distintos niveles, sufrieron una reordenación simbólica a partir de la nueva acepción de Ciencia y Tecnología. Una transformación del ecosistema académico, una reforma urbana del laberinto que tanto nos gusta imaginar como analogía de los saberes. Este cambio, que se intensificó durante el siglo XIX y el XX, y que para muchos puede haber parecido una promoción o avance, para otras áreas -llamémoslas clásicas- representó un desarreglo que abarca más que simplemente un cambio de recorrido entre las estanterías. Sucintamente, en este ficticio nuevo orden Dewey, todo quedaría bajo la numeración 500 y 600, de Ciencia y Tecnología, respectivamente, y el resto de las divisiones estándares y subdivisiones, del 000 al 400 y del 700 al 900 , se subordinarían. Como bien lo expresa Latour en su libro Nunca fuimos Modernos: "Es evidente que nuestra vida intelectual está muy mal hecha. La 
epistemología, las ciencias sociales y las ciencias del texto, cada una tiene su casa propia, pero a condición de ser distintas. Si los seres que a ustedes les interesan atraviesan las tres, dejan de ser comprendidos" (21).

Históricamente, la ofensiva inicial contra esta posible contaminación interdisciplinaria la dio la filosofía platónica frente a las fuerzas artístico poéticas, asociadas a la ficción, a los mitos. Luego, con la primera modernidad, las ciencias aplicadas y teóricas, como nuevo principio regulador universal, reordenarían las disciplinas según criterios relacionados con su utilidad, la producción y la vida humana. Con el tiempo, las prácticas identificadas con las ciencias naturales instituyeron un formato de escritura que se acomodaba a la presentación de sus investigaciones, eficiente en la exposición de las hipótesis y los resultados de los experimentos correspondientes. Si bien esta práctica científica tuvo su propio desarrollo como formato de escritura y análisis, la absorción de las academias científicas por parte de las universidades, a partir de la Ilustración, y, paralelamente, la generación de organismos reguladores centralizados de los Estados nacionales, buscaron estandarizar los procesos, criterios e incentivos, tratando de alcanzar la mayor eficiencia posible. Si se buscan culpables, sin duda uno de los primeros en resaltar será René Descartes. Su iniciativa racionalista, plasmada inicialmente en el Discurso del Método (1637), es identificada con el comienzo del avance de una noción de Verdad impulsada por una fuerza ubicua que, paradójicamente, se aleja de una retórica específica, imprimiendo incluso una ausencia radical de retórica al discurso científico (Nancy 66). Se trataría del estilo más propio de la razón, representado para la posteridad por el propio Descartes desde su doctrina -a pesar de él- y corregido por la mano crítica de G. W. Leibniz, proyectado posteriormente por Ch. Wolff, con nuevas variaciones. Curiosamente este giro, finalmente estilístico, sobresale aún más si lo apreciamos en paralelo con la fundación de otra disciplina en el firmamento del siglo XVIII: la estética, representada por la figura de A. Baumgarten, heredero directo de los filósofos antes mencionados.

Alexander Baumgarten acuña algo más que un concepto, se trata de un ámbito que excede los límites del saber racional, alcanzando los del sentir. Por lo tanto, no tan solo es posible identificar la recepción del modelo cartesiano en un sentido científico, sino también estético, incluso, filológico. De hecho, la propuesta de Said en The return to the philology nos habla de un método ampliado, al vincular la relación interna y externa del texto con una estética que lo abarca, no solo desde la forma sino desde la raíz decisional que todo texto implica, ya sea escrito o leído (62). 
De este modo, la estilística científica puede relacionarse con la constitución paralela de una retórica de lo sensible. Extendida a una dimensión emotiva, la estética se abre hacia un concepto de sensibilidad articulado por la razón y hacia un cosmos científico complejo. En un ejemplo tomado de una sección de la Aesthetica, publicada en 1750, Baumgarten plantea, entre otras categorías, aquella de "un amor poético de lo verdadero" (XXXVI §585). Mientras, al mismo tiempo, sus textos asumen la forma de un tratado de lógica estricta. De este modo, ya no identificamos el proceso de avance del racionalismo cartesiano solo con la dominación del principio cientifizante del método, sino como un crecimiento equilibrado hacia "el conocimiento sensible", propuesto por Baumgarten para -incluyendo esta dimensión- comprender lo humano (I §1).

\section{LA VENERACIÓN DE UN ESTILO, CONTAMINACIÓN INTERDISCIPLINARIA}

Con el paso de los siglos en la modernidad, la escritura de las ciencias y el avance de los sistemas de información computarizados de la segunda mitad del siglo XX incentivaron una forma totalizadora de transmisión del conocimiento objetivo, un género discursivo específico, conocido como paper o artículo cientifico. Hoy, dicha práctica ha alcanzado el grado sumo de penetración en la academia y pareciera no declinar en su avance hacia la dominación total. Es posible preguntarse, entonces, si acaso no es necesario advertir o, al menos, imaginar algunas de las consecuencias que trae la veneración de una práctica que supone un único formato, estilo y método, como si su adquisición absoluta fuese inocua respecto de la diversidad de disciplinas y quehaceres.

Pareciera haberse olvidado que las ciencias en sus orígenes compartieron un espacio intelectual común con el discurso de lo sensible, durante, precisamente, la emergencia de cada nueva forma de saber. Quizás, un ejemplo indicativo de este origen común sea el hecho de que hoy se escuche con fuerza el discurso de la interdisciplina y la innovación, más allá de la intensificación de los procesos en los que se busca unificar y estandarizar las prácticas. Si bien es fundamental favorecer la comunicación humana, el incremento del acerbo de información y datos, así como su sistematización, ciertamente deben adecuarse a sistemas de búsqueda y recuperación automatizadas, aunque esta premisa no puede ser la única condicionante y su destino. Sobre 
todo, porque el catálogo de saberes con que dialoga, tal como lo imaginaron Descartes, Leibniz, Wolff o Baumgarten, sigue implicando no solo la razón, sino un ser humano, un cuerpo. La tendencia a la uniformidad no se asocia solo a lo práctico, sino que impone dinámicas y procedimientos determinados. Esto - sin pecar de ingenuos- es posible porque las humanidades y las artes, que cultivaron tradicionalmente un discurso propio de la estética, fueron atraídas por la fuerza gravitacional y el prestigio que proyecta el discurso científico, asociado a la tradición racionalista. Tendencia que, a pesar de venir de un contexto en el que ambas disciplinas emergen, tanto el discurso estético como el científico -quizás porque el primero parece más un arte y el segundo no- asumen la predominancia de este último y, por lo tanto, de un estilo retórico eficiente al que todas las disciplinas deben aspirar: llegar a ser ciencia, hablar como ciencia.

En este marco de responsabilidad compartida, entre ciencias y humanidades, surge la pregunta sobre las consecuencias, aparentemente insubstanciales, de la relación entre forma y utilidad estilística, la que no puede pensarse como simplemente externa, en un sentido formal. Es precisamente esta convergencia, forma y contenido, la que permite deducir que asistimos a una transformación de una estética del conocimiento, por el señorío de una retórica pseudo-científica.

Baumgarten, en 1750, adelanta una ponderación especial para los estudiosos de la ciencia del conocimiento sensible conocida como estética, señalando que: “[...] según el constante amor por la verdad, en cada caso, cualquiera sea la especie de verosimilitud por él seguida, e incluso cuando es poeta y se manifiesta de modo agraciado [...] entonces será, a mi juicio, un investigador digno de la naturaleza y lo verdadero" (XXXVI §613).

\section{EUGENESIA EPISTÉMICA: HOMOGENEIDAD Y DESEO DE OBJETIVIDAD}

En la actualidad, con el débil reflejo que aún proyectan las palabras de Baumgarten, en el caso de las revistas científicas, con sus procesos y formatos establecidos, pareciera imponerse una forma exigente de eugenesia epistémica. Como si entre las oficinas de las universidades circulara un único y mismo memorándum, buscando establecer métricas y patrones homogéneos para evaluar sin diferencias. Dicha estandarización es comparable con la decisión tomada por la Comunidad Europea cuando, tratando de realizar el sueño 
de la unión económica, iguala la moneda, acarreando con esto, lo que hoy sabemos, significó una crisis, local y global. Un trance político derivado de una crisis de traducción, al tratar de borrar las diferencias - de las naciones, en el ejemplo-y las características propias de las disciplinas, en la analogía que proponemos. Convertir todo a un solo patrón puede ser muy útil, pero también perjudicial, sobre todo si esto implica volver equivalente proporciones imposibles.

Michel Serres, al inicio de un libro que una vez publicado tuvo características predictivas, en el año 1996, respecto de los poderes de la World wide web, recuerda con agudeza cómo se ha transformado el hábitat del conocimiento en los últimos siglos; cuáles han sido las disciplinas expulsadas una vez que definitivamente mueren o mutaron los últimos vestigios del Medioevo. Entre otras manifestaciones culturales vimos desaparecer: la historia natural, los meteoros y la astrología; hoy convertidos en rótulos inexistentes de clasificaciones bibliológicas intersticiales (13). ¿En qué se transformaron? En climatología, astronomía, mitología, iconología, es decir, en ciencias "ciertas". Anaqueles posibles de ordenar, clasificaciones comprensibles, pero no por eso inocuas respecto de la búsqueda misma. El cielo ptolemaico con sus figuras míticas estalló; lo que queda son miles de estrellas con nombres y constelaciones sin poder sobre nuestras vidas, pero con todo el poder de la física sobre el mundo. Ahora somos nosotros los que tenemos poder sobre ellas, las designamos con un número, las vectorizamos. En el caso de las formas cifradas de la escritura académica, hemos visto estallar los géneros, alcanzando un cosmos racional científico -salvo algunas excepciones- en los que el oportunismo cultural disfrazado de crítica, hace pasar, a veces, el arte por ciencia, cuando no el pillaje por creatividad, y la usura moral por ética y política.

¿Cuál es el principio que apoya el establecimiento de un área del saber? Simple, los limites: "Dime lo que excluyes, y te diré lo que piensas" (Serres 92). Es el momento en que comienza un ciclo del que aún no salimos, a pesar de las avanzadas interdisciplinarias, en las que los campos van distanciándose, sin fundirse en un trabajo en grupo sinceramente equitativo. Las ciencias parecen quedarse a solas con la verdad, como una diosa que pide luz propia, sus rayos proyectan aquello que llamamos objetividad. El aislamiento, lo que en realidad instala, es la desvinculación de las disciplinas con su propia historia, con sus juegos de lenguaje y, finalmente, con sus metáforas. Se emplaza un modelo fundado en principios que imaginamos constantes y que se vislumbran en las áreas de exclusión por especificidad. El hecho de poseer 
una teoría que piensa lo que pensamos en su totalidad (epistemología) y, en proporción directa, la instalación del principio de obsolescencia, es decir, la constitución de ciencias sin historia, se vuelve un hecho radical (Rossi 188). Luego, las consecuencias son patentes: "La objetividad es una visión ciega, una mirada sin inferencia, sin interpretación, sin inteligencia" (Danston y Gallison 25).

Serres va más allá y plantea directamente la sentencia: "El elogio y la publicidad de las ciencias canónicas se llama, de manera noble, epistemología" (92). El proceso hacia los secretos y las verdades - cada vez más pragmáticas, al mismo tiempo que más efímeras, pero no por eso menos dominantes-revela las condiciones de experimentación. Lo que demuestra que finalmente la batalla entre ficción y verdad no tenía tanto que ver con la expulsión de las artes y la poesía de la República utópica, sino con cómo la ciencia, como criterio general, incluida la filosofía de la ciencia, dominaría completamente el modelo académico global.

El principio narrativo que hay detrás de esta configuración, que describimos someramente, y la ilusión de haberse liberado de la retórica, se debe a los ya arcaicos principios de progresismo, especificidad, absolutismo y obsolescencia. Por ello, el foco de interés está cada vez más en "lo nuevo", lo específico, las pruebas y sus deprivaciones experimentales, grupos de control y exclusiones, procesos que no hacen sino cubrir para ocultar lo que luego aparece como confirmación de las hipótesis y preguntas de investigación. Una administración renovada del "secreto", bajo los destellos de una no-retórica científica y, por lo mismo, exacta.

No obstante estos nuevos límites del conocimiento, en la ciudad ideal científica, protegida por la muralla metódica -a pesar de la creciente forma de sedentarismo académico- cada nuevo desplazamiento del entorno demuestra la necesidad de mantener otras formas más amplias de mirada y visión, que consideren los procesos que fueron inevitables para llegar hasta el lugar donde se emplazó aquella fortaleza. Así, se hace necesario considerar cómo cada nueva revelación afecta otras áreas del saber, pero también la vida cotidiana y la del espíritu, y -en última instancia- recordar los rastros, personas y grupos que consintieron, como una caravana de nómades, llegar hasta este nuevo emplazamiento. Char anuncia la mutua necesidad en que se basa esta perspectiva, en la prosa lacónica del poemario Aromas Cazadores: "El presente-pasado, el presente-futuro. Nada que preceda y nada que suceda, solo las ofrendas de la imaginación" (503). 
Porque, tal como lo presentan Danston y Gallison, incluso la objetividad misma como criterio tiene su historia y estilo, en la que necesariamente debemos diferenciar certeza de verdad, con aquella más reciente y ansiada de objetividad (25). Nuevamente, las premisas que señalábamos antes cobran presencia y reclaman las amplias perspectivas por las que se alcanzó la especificidad o especialidad. Y aunque muy cerca podamos suponer que la ciencia ha llegado de la verdad, lo que en realidad ocurre es que solo ha ido cerrando el punto de enfoque respecto del mundo que excluye. Sin considerar, además, el hecho de que para poder luego transmitir dicha experiencia objetiva, requiere de elementos que la misma especificidad disciplinaria ha dejado fuera, por considerarlos innecesarios, como por ejemplo, el lenguaje (en un sentido amplio del término, pero sobre todo retórico) y, ese lenguaje, un cuerpo y un mundo, lo que vuelve a vincularse con los paradigmas poéticos y retóricos que parecían descartados de aquel cosmos.

Resuena con fuerza la propuesta de Emerson, en 1841, cuando señala que "la naturaleza es una disciplina. La noción de mundo que surge y la relación que identifica incluye los usos precedentes, como partes del mismo" (20). Hoy podemos comprender que, del mismo modo, la disciplina se ha vuelto naturaleza. Y como toda naturaleza, salvaje, voraz y -si nos medimos con ella- ferozmente injusta. Incluso trágica.

\section{EL LENGUAJE DE LAS CIENCIAS, AUTOIMAGEN DE LAS HUMANIDADES}

Si bien en un momento la ciencia luchó por establecer una diferencia radical entre su discurso exacto y el "libro del mundo", que por sus características demiúrgicas comenzaba a incomodar, dado que apelaba no tan solo a la naturaleza como texto, sino insistía en suponer un autor o un creador personificado. El laicismo generó un nuevo registro para aquel libro, escrito con las cifras objetivas, en lo que se llamó la historia natural y luego las ciencias biológicas, sociales... y los demás complementos. Ahora, ¿por qué suponemos, tan fácilmente, que detrás de ese pasado analógico permanece la raíz mítica y, por lo tanto, errónea, que malentendía de forma mágica el mundo? ¿No estaremos levantando, una y otra vez, una nueva forma de animismo arcaico, solo que con otros tótems y esta vez la dominancia teogónica la tienen simple y temporalmente la razón y la ciencia? Blumenberg observa: 
Incluso la experiencia moderna, de índole científica, hizo, en gran medida, su autoproclama frente a la dominación de un solo libro o la sanción de unos pocos libros, e incluso se auto-legitimó echando mano de una metáfora libresca sobre sus realizaciones teóricas. Únicamente quien crea que la empírea teórica de la Edad Moderna es lo más natural del mundo, una accesibilidad inmediata a las cosas -que solo precisaba ser descubierta para ser aceptada-, puede considerar una mera redundancia retórica el que esa nueva propuesta se hiciera en un lenguaje de rivalidad con el libro, movida por el impulso de sobrepujar ahora todas las formas anteriores de legibilidad (La Legibilidad 13).

Y si bien no se trata de arrogarse la formación de una crítica científica general, parafraseando otro pasaje de esa misma obra de Blumenberg, sí es importante establecer el grado de influencia que estas prácticas implican y cómo esto ha afectado el ecosistema académico. La relación entre las cosas y la representación siempre ha supuesto una serie de mediaciones (Hallyn, Les structure rhétoriques 11), entendiendo que, como decíamos antes, nuestro lenguaje implica una mente y la mente un cuerpo y ese cuerpo un mundo. ¿Cómo describimos lo que vemos si no asumimos que se basa en una representación de una experiencia siempre inicialmente sensible?

Es evidente, en todo caso, que cualquier voluntad que intente devolver o refundir las acepciones epistemológicas con una poética originaria (en un sentido filológico), que entiende el descubrimiento del mundo y sus razones -dando razones que hoy pueden parecernos infantiles- implica superar el temor a entrar en una "retórica profunda". Este paso implicaría explorar las formas, así como la generación de las representaciones mismas en un sentido general. Lo que hoy pensamos y deducimos, aunque no queramos, con el tiempo también será digerido como error, es decir, como mito. Esta es una de las leyes de la obsolescencia científica, así como de la supervivencia estética.

No es fácil asumir la diferencia entre el desarrollo de una capacidad semiótica del mundo, de una simplemente sintáctica. Ni es sencillo comprender aquel universo simbólico pre-racional, impuesto por leyes incomprensibles que se superponen en una pre-historia del conocimiento. La legibilidad, como lúcidamente explica Blumenberg, es un proceso constante sin superación posible. El punto ciego de la objetividad que describen Danston y Gallison solo puede atenuarse, no curarse; se desplaza, nunca se alcanza. Se trata de procesos y resultados, que bien pueden abarcar el círculo completo del conocimiento humano, aunque no es fácil que sean asumidos por las instituciones. Reside en permitir una apertura, casi utópica ya, hacia procesos 
científicos con resultados poéticos o resultados poéticos a partir de procesos científicos (Aby Warburg cit. en Didi-Huberman 143). El juego silogístico deja entrever la crisis de la noción progresiva de ciencia, pero también la de arte, sobre todo si además sinceramos cuánto de la búsqueda entendida como apertura y exploración de los secretos del mundo, se ha vuelto una repetición burocrática de prácticas (Hallyn, Les structure rhetoriques 29-31).

Como recuerda el propio Hallyn, Mallarmé, en 1869, escribe una nota muy sugerente que vuelve sobre la relación cartesiana que proponemos al inicio de este breve estudio: "Todo método es una ficción, buena para la demostración [...] la ficción [...] parece ser el procedimiento mismo del espíritu humano - es el que pone en juego todo método, y el hombre se reduce a la voluntad. Página del Discurso sobre [sic] el método" (Mallarmé cit. en Hallyn, Les structure rhétoriques 123 ).

¿Cómo fue que llegamos a la idea de que se trataría de "un solo" método para todo el conocimiento? Y si es así, ¿qué modelamiento implica para las áreas que no necesariamente tienen un objeto de estudio definido - $\mathrm{o}$ de objetos confusos como los llamaría el propio Descartes-y que comprende la imposibilidad de subdividir el todo en partes tan pequeñas como simples, de modo que la claridad de la razón las ilumine hasta volverlas transparentes?

Porque, como bien señala Melandri, "que la ciencia posee una poética particular de ella, está fuera de duda", sin embargo, "[...] excluir la poética de la ciencia equivale a excluir la hipótesis" (Menlandri cit. en Hallyn, La structure poétique 9). Ahora bien, ¿qué han perdido las humanidades al tratar de zafarse de sus propias poéticas y retóricas, al aspirar con tanto ahínco a volverse ciencia? ¿Qué hipótesis pueden construir, qué analogías tramar en un ámbito del saber que fue cediendo todos sus espacios para poder acceder al prestigio que, desde la Ilustración, solo posee la ciencia? No basta con asumir que la metáfora tiene una lógica o incluso que el texto posea una irracionalidad, que habla desde el inconsciente del lenguaje en las zonas oscuras que son pasto de la crítica conocida como epistemología.

El problema es más profundo, la secuela más potente; es el resultado de un quiebre semiótico cultural, debido al deseo transversal de las humanidades y las artes por no perder o cambiar su rol. Ansias de poder, de participación en la repartición del juicio, volviéndose juez, cuanto más cerca se está del valor de verdad. Aunque esa verdad ya tiene poco que ver con una cosmogonía estética. Baumgarten opone - más bien diría, presagia- la noción de amor a la belleza con el amor a lo verdadero que, por cierto, las prácticas contemporáneas no contemplan necesariamente, debido a que una pragmática específica las 
supera y determina. Amor, para no hablar de belleza, ya que dicho concepto está aún más debilitado. Mientras, para la ciencia será cada vez más clara la necesidad de entrar en una tropología que Hallyn imagina derivada de: "[...] los modelos formales de procedimiento que el sujeto puede adoptar en sus transformaciones conceptuales de representaciones convencionales. La teoría de los tropos es una teoría del abandono de la convención semántica y de la innovación de las representaciones" (La struture poétique 31).

Sin duda esto tiene consecuencias para todos. ¿Cómo resolver el problema inversamente proporcional de una ciencia que intenta siempre una nueva hipótesis, a partir de nuevas metáforas, y de una poética que con las mismas metáforas busca volver hipótesis, procesos que no son sino descripciones, caracterizaciones, trazos de mundos que se desvanecen, relatos, débiles huellas, del mismo modo como inmensas revoluciones? Se forma así un coro compuesto de voces al unísono, caótico quizás, pero al menos ya no un sistema que imagina un canon por sustracción, eliminando a unos y otros por obsolescencia u error. Danston y Gallison afirman:

La noción de verdad a partir de la naturaleza se vio modificada por la aparición de alternativas que a veces estaban en oposición. Así mismo, el juicio no tuvo el mismo sentido antes y después de la aparición de la objetividad. Aquello que había sido un acto de razón práctica deviene una intervención de la subjetividad, ejercida de manera defensiva y ofensiva (27).

La armonía perfecta de un racionalismo o sus variaciones más rectas o escépticas llegó a su fin. Pocos están dispuestos a sostener una ley, sino más bien disfrutan de los vaivenes que el devenir de lo verificable produce. La ciencia supo asumir la inestimable ventaja del carácter provisorio de sus resultados. Ese mismo parámetro, en las humanidades y las artes, se vuelve la inoculación de su propia decadencia. De alguna manera, el pensamiento dinámico que representaban algunos filósofos es una señal de las vías y de los métodos "alternativos", que se vuelve urgente re-imaginar. El problema es suponer que esto no implica cambiar la forma o estilo del texto, a pesar de la diversidad del contenido.

Como bien señala Kenneth White, la gracia está en que "a diferencia de Sócrates que piensa la ola, Heráclito piensa como la ola" (White cit. en McManus 96). De este modo, podemos rastrear en los orígenes mismos de las descripciones que Occidente ha elegido como formas y figuraciones de la sensibilidad y del saber, una clave que delata la tendencia a un absolutismo 
epistemológico. Fuerza que, a partir de mediados del siglo XIX, vemos asociada a una matematización de sus formas y procesos que ya venía del racionalismo del siglo XVII y que, para dicho contexto, fue positivo y fundamental. No obstante, con el tiempo, esta tendencia influyó, como todo sistema complejo, desequilibrando otras variables como, por ejemplo, la descripción tanto sintética como analítica y también simbólica; socavando aspectos difusos asociados a poéticas y retóricas que formaban parte del hacer de las artes y humanidades y -como lo describe Bekermann- de su particular "aprender/saber" (14).

\section{TODO MÉTODO ES UNA FICCIÓN}

La obra de Gaston Bachelard proyectó, a principios del siglo XX, los márgenes que hoy alcanzamos, al identificar que -como toda racionalidad-la ciencia también tiene una fase inconsciente, e identifica los límites que vive el conocimiento. Estas demarcaciones remiten, primero, a la experiencia, luego, al conocimiento general o previo, al obstáculo verbal y el uso excesivo de imágenes familiares entre otras, $\mathrm{y}$, finalmente, a dificultades como el sustancialismo, el realismo y el animismo (15). Series consecutivas, no excluyentes o paralelas, a las que debiéramos sumar precisamente aquel factor retórico asociado a la interpretación del mundo y los hechos, así como los lenguajes que permiten su percepción, comprensión, comunicación, tanto verbal como visual -y audiovisual, por cierto-y que tiende a sintetizarse en la metáfora del lenguaje. Proceso que muchas veces es asociado únicamente con su locación cerebral, pero que debe entenderse de modo multirrepresentacional y, además, implicando campos complejos del juego de encaje semántico entre lenguaje, mente y cuerpo; articulado como un proceso recursivo y en ampliación constante, salvo accidentes y contingencias.

Descubrir, interpretar, deducir, siempre fue un arte, en el mejor sentido del término. Hoy, de algún modo y a pesar de que no podemos generalizar, al menos en el ámbito académico de las humanidades y las artes, es patente que asistimos a una corriente burocrática, temporalmente eficiente, dedicada a la producción de páginas y páginas pulidas por un criterio completamente ficcional de ciencia y, en gran medida, alejado del amor por el conocimiento o su belleza.

Ahora bien, evidentemente, esto no es culpa de la ciencia y su ejercicio particular, entendido como una entelequia que domina desde las sombras; 
figurada como una inteligencia determinada $y$, mucho menos, como una voluntad específica. Sino, por el contrario, es fruto de un proceso social más amplio, pero no en el sentido acostumbrado, sino entendido como consecuencia de las sociedades científicas, academias y universidades, que -en el ámbito de las humanidades y las artes- experimentaron el proceso de la Ilustración y sus nomadismos posteriores, como un deterioro en directo perjuicio de su autoimagen. Una transformación vivida como acomplejamiento, un bastardismo, una carencia que fue buscando validarse a través del travestismo retórico científico que está comenzando a revelarse nocivo. Recordemos el planteamiento de Emerson cuando imagina de antemano las implicancias de una avasalladora homogeneización del cosmos:

Una campana y un arado tienen cada uno su uso, y ninguno puede hacer el oficio del otro. El agua es buena para beber, el carbón para quemar, la lana para vestir; pero la lana no puede ser bebida, ni el agua hilada, ni el carbón comido. El hombre sabio demuestra su sabiduría en la separación, en la gradación; y su escala de criaturas y de méritos es tan amplia como la naturaleza (21).

Esto no implica que las ciencias no vivan sus propios procesos, crisis y travestismos en paralelo. Basta ver el realce que experimentan nociones como las de creatividad, innovación y gestión del conocimiento, como promesas de recuperación de energías que podemos llamar, sin riesgo de exagerar, artístico-poéticas. Más aún, mientras vemos cómo todas las disciplinas, unas más que otras, están entendiendo el rol de la divulgación, que siempre ha existido y es esencial para la continuidad de la posta que el conocimiento implica. Por otra parte, toda la institución académica espera que los pequeños productores de papers e investigaciones se centren en lo específico, no del tema, sino de los proyectos y los fondos para sustentarlos. Emerson advierte, hace más de un siglo, esta tendencia triunfal de la especificidad centrada en un conocimiento intensivo:

Estamos aquí de nuevo impresionados e incluso intimidados por el inmenso Universo por explorar. "Lo que sabemos, es un punto comparado a lo que no sabemos". Abrid cualquier revista científica reciente y considerad los problemas sugeridos concernientes a la luz, el calor, la electricidad, el magnetismo, la fisiología y la geología, y juzgad si es que el interés por las ciencias naturales está cercano a ser agotado (22). 


\section{LAS CIENCIAS HUMANAS O EL ERROR SIN CULPA DE LAS HUMANIDADES}

Algo ya nos anticipaba la llegada de un nombre de fantasía que se usa desde hace casi dos siglos para designar algunos de los campos categoriales: las ciencias humanas. Una fórmula que buscaba salvar ciertas áreas de las humanidades y de la antropología que corrían el riesgo de caer en los disparates poéticos del siglo XIX. La atracción del halo de la verdad racional llevó a abandonar la retórica, la misma que a veces es culpada por "las consecuencias que implica la posesión de la verdad o de las dificultades que resultan de la imposibilidad de alcanzarla" (Blumenberg, L'imitation 92). Pudimos haber explotado lo difuso, lo obscuro y lo confuso que siempre funda toda experiencia de conocer el mundo, y haber hecho de eso una ciencia o un arte. Sin embargo, lo que no entra en ello, lo inexacto, lo erróneo, como opuesto a lo claro y distinto, lo verdadero y lo cierto, no pueden ser excluidos. Esa experiencia es también parte de una retórica y una estética del conocimiento, propia de la experiencia del secreto que la ciencia disfrutó y aún disfruta.

¿Qué fue lo que ocurrió entre las divagaciones que iluminaron el pensamiento? ¿Cómo se alcanzó la ansiedad científica que ha llevado a las disciplinas a someterse a una forma funcional estilística, con tal de obtener el estatuto o condición de ciencia? ¿Quién no anhela anteponer el término ciencia a su disciplina, de manera de ser más, de ungirse con la exactitud, bajo la reputación de una razón sin historia que trabaja seriamente? Una suerte de impulso por resolver la renegación de la madre Razón, la que a veces olvida otras zonas que formaban parte de las artes. La tendencia radical por la novedad como vaticina D. Maquieira -en su libro poema visual El Annapurna- nos hace olvidar que "el curso trasciende el rumbo" ( $\mathrm{s} / \mathrm{n})$.

Bachelard llamaba a los historiadores de la ciencia, a mediados del siglo XX, a tomar consciencia y separar los objetos de estudio del proceso de comprensión, así como de la forma que adquiere para su socialización. Bachelard escribe:

El historiador de la ciencia debe tomar las ideas como hechos. El epistemólogo debe tomar los hechos como ideas, insertándolas en un sistema de pensamientos. Un hecho mal interpretado por una época, sigue siendo un hecho para un historiador. Según un epistemólogo es un obstáculo, un contrapensamiento (20). 
Se trataría de una reserva para el futuro, para un futuro del conocimiento que no olvida los orígenes difusos de toda forma de conocimiento, justo antes que se transforme en un área, un campo del saber y, por lo tanto, en un espacio posible de agenciar, administrar y, por cierto, expropiar al devenir de la creatividad y la innovación. Son estos los límites que se desplazarán, mientras asfixiamos - por medio de formatos optimizados- los lenguajes en que representamos, demostramos y explicamos aquella búsqueda sin un destino preciso. Serendipity, como se nombra a quien halla lo que no busca.

La única forma de comprender la emergencia del conocimiento es comprender la fugacidad de sus demarcaciones. La necesidad de la oscuridad para la luz, en una reciente y siempre ambigua aventura interdisciplinaria, que se anuncia como un nuevo acuerdo para las humanidades, pero que quizás no sea sino el "caballo de Troya" para el asalto final. Los mismos conceptos que la ciencia está valorando en la actualidad, paradójicamente, vienen de la cuna de la poética, supuestamente, más sospechosa. Creatividad, innovación, deriva, son practicas arcaicas para las artes, la poesía y la retórica. Asumámoslo, no son las ciencias las culpables, como si pudiéramos imaginar una voluntad o entelequia detrás de todo esto. Mejor es recuperar un concepto igual de antiguo, y pensar que, lo que nos trajo hasta acá, quizás, como en todo lo humano, es una forma de hamartia. Lo que en la tragedia griega era reconocido como "el error sin culpa" y que funda la noción de destino que el héroe indefectiblemente experimenta. Quizás, en esto también, tal como en la tragedia, lo humano del conocimiento permite comprender cómo la hamartia de las humanidades, en la complacencia científica, es el error sin culpa que funda la ceguera que la propia razón traía como antorcha. En palabras de Bachelard: "El conocimiento de lo real es una luz que siempre proyecta alguna sombra" (15).

Pero volvamos quizás a un aspecto puntual del planteamiento que hemos seguido, para intentar establecer relaciones entre el trabajo intelectual y el mal llamado método científico, el que ha sido reducido a una forma-función sin crítica, y, como uno solo, por ende, carente de belleza. Una posibilidad es pensar que todo este fantasma del paper se alza contra las humanidades, tratando de debilitarlas de su poderío. Sin embargo, también sería constructivo pensar si acaso no fueron las mismas humanidades que se traicionaron a sí mismas. Que creyeron que podían asumir este género como algo externo. Que podían levantar la espada de la crítica sin herirse. El aparente abandono de una retórica, en el sentido clásico, abrió paso a una fingida estructuración científica, metódica del estilo y la forma de circulación preferente del conocimiento, 
el paper, es el síntoma. Imputar a la ciencia de dicha transformación, sería absurdo, por el contrario, indagar en las ambiciones de las humanidades y las artes, al suponer que la transformación del estilo podía quedar solo como un aspecto externo, sin determinar a la larga radicalmente su contenido, puede ser un camino para un nuevo acuerdo cultural.

Descartes pensó un método para la ciencia, porque lo creía urgente, nunca su intención fue la de conquistar cualquier producción intelectual bajo paradigmas esquemáticos absolutos, abarcando además los formatos, las obras y los procesos que no fueran propios de lo buscadamente científico. Sería inconsecuente. Sin embargo, ya estamos en una etapa posterior: la cientifización, que como forma de prestigio, tiene su "retórica no retórica". Ni el discurso, ni siquiera aquel olvidado Discours legado por Descartes, que nada tiene de paper. La razón que se nos da cuando buscamos el porqué de estas maneras es que se cierne el espectro del desorden, la imposibilidad del retrival, la pregunta por cómo volveremos a dar con tal o cual dato, autor o fórmula, en una pesadilla de Ranganathan. Pero el orden es una razón mezquina comparada con la pérdida de diversidad de formatos y acuñamiento de la información, así como de la transmisión del conocimiento en sus formas más diversas. Basta pensar en la analogía posible con las especies que se extinguen. Alguien dirá que es la ley de la vida. Sin embargo, en el caso de las instituciones del saber, pareciera que éstas nunca mueren definitivamente sino solo se degradan (Serres 13-14).

Una posibilidad es pensar esta situación derivada de lo que René Char en su poema Lomos describe, primero, desde un ángulo de autocrítica con una elocuente imagen: "Fracaso de la filosofía y del arte trágico, fracaso que solo beneficia a la ciencia-acción, la ejecutora, la pordiosera con su cacerola, convertida, con sus rostros homicidas y sus travestidos, en barquera de nuestra vida hibridada, asunto trivial" (511). Más adelante, en segundo lugar, en el mismo poema Char escribe: "Una ciencia autoritaria se despega del grupo de sus hermanas modestas y se mofa del prodigio de la vida, del que extrae una moneda sin miedo. Siempre la idea envileciendo el objeto; la bestia se ha vuelto fabulosa y espumosa..." (513).

Quizás, la mayor aspiración sería que luego de haber terminado la batalla específica por la relación de sujeto-objeto, lo que surja sea el mundo o, al menos, una visión de éste como otra posible cosmovisión. Recordemos que la palabra cosmos, en su origen, significa ornamento y no solo orden. Ahora bien, es un mundo que no puede volver a ser el "libro del mundo" así no más, en la escritura cifrada de la retórica demiúrgica, porque se ha vuelto apenas 
los capítulos sueltos de una reescritura del "libro de la naturaleza". Porque, quizás algún día, se logre esclarecer las consecuencias de la transformación de una cultura del libro del mundo, al mundo del libro, y luego a su estallido en el mundo del paper. Ahora bien, vale la pena insistir: es una consecuencia, no una desgracia inesperada.

Primero, la disputa fue con los libros o por los libros, pero en relación con los discípulos y el diálogo que articulaba la memoria en profundidad y sus formas de transferencia (Blumenberg, La legibilidad 71). Luego con los libros mismos como reserva de lo obsoleto y también de lo falso -como el propio Descartes lo anuncia. Caemos una y otra vez en la trampa de la actualidad, quizás esta disputa no sea sino una nueva versión de la vieja querella de antiguos y modernos, quién sabe. La novedad por la novedad, la antigüedad por la antigüedad, son temas de prestigio. Unos alegan que no se puede permitir la falta de originalidad de una filología pasatista y, del otro lado, se divisa la cabeza erguida que mira el presente de un porvenir que se supone distinto a un discurso absoluto. Ante esta sobrecogedora multiplicidad de rutas, quizás valga la pena tomar el partido del explorador y el peregrino, que en lugar de enarbolar la bandera uniforme de la conquista, se sume en las cavilaciones gustosas de la complejidad. "No es imposible que la Torre de Babel continúe proyectando su sombra creadora" (8), palabras de George Steiner.

\section{BIBLIOGRAFÍA}

Bachelard, Gaston. La formación del espiritu científico: contribución a un psicoanálisis del conocimiento objetivo. Trad. J. Babini. México: Siglo XXI, 2010.

Baumgarten, Alexander. Estética. Trad. it. F. Caparrotta et al. Palermo: Aesthetica, 2000.

Bekerman, Svy. “Aprender/saber”. Revista Decisio, Septiembre-Diciembre, 2011.

Blumenberg, Hans. “Approche anthropologique d'une actualité de la rhétorique”. L'imitation de la nature. Paris: Hermann, 2010.

La legibilidad del mundo. Trad. P. Madrigal. Madrid: Paidós, 2000.

Char, René. “Aromas cazadores”. Poesía esencial. Trad. De J. Riechmann. Barcelona: Galaxia Gutemberg, 2005.

Danston, Lorrain \& Gallison, Peter. Objectivité. Trad. fr. S. Renaut, H. Quiniou. Bruxelles: Les press du réel, 2012.

Didi-Huberman, George. L'image survivante. Paris: Minuit, 2002.

Emerson, Ralph Waldo. "Nature". The complete essays and other writings. New York: Random House, 1940. 
Halllyn, Fernand. La structure poétique du monde: Copernic, Kepler. Paris: Seuil, 1987. Les structures rhétoriques de la science: de Kepler a Maxwell. Paris: Seuil, 2004. Latour, Bruno. Nunca fuimos modernos. Trad. V. Goldstein. Buenos Aires: Siglo XXI, 2007. Maquieira, Diego. El Annapurna. Santiago: D21, 2013.

McManus, Tony. The Radical Field: Kenneth White and Geopoetics. Dingwall: Sandstone Press, 2007

Nancy, Jean-Luc. Ego sum. Paris: Flammarion, 1979.

Rossi, Paolo. El pasado, la memoria y el olvido. Buenos Aires: Nueva Visión, 2003.

Said, Edward. "Return to the Philology". Humanism and Democratic Criticism. New York: Columbia University Press, 2004.

Serres, Michel. Atlas. Paris: Champs - Flammarion, 1996.

Steiner, George. Después de Babel: aspectos del lenguaje y la traducción. Trad. A. Castañón México: Fondo de Cultura Económica, 1980. 